\title{
Исследование сорбционно-газохроматографического определения полихлорированных бифенилов в маслах
}

\author{
Первова М.Г. ${ }^{1}$, Плотникова К.А. ${ }^{1}$, Шатунова Т.В. ${ }^{2}$, Салоутин В.И. ${ }^{1}$ \\ ${ }^{I}$ ФББУН Институт органического синтеза им. И.Я. Постовского УрО РАН, Екатеринбург \\ ${ }^{2}$ ФГАОУ ВО Уральский федеральный университет им. первого Президента России Б.Н. Ельцина, \\ Екатеринбург
}

Поступила в редакцию 1.12.2017 г.

DOI: https://doi.org/10.17308/sorpchrom.2018.18/530

Проведено исследование использования многослойных сорбционных колонок, в состав которых включены сорбенты различной природы (силикагель, полихром-1, полисорб-1, флорисил или оксид алюминия), для извлечения смеси полихлорированных бифенилов (ПХБ), содержащей ди-, три-, тетра-, пента-, гекса- и гептахлорбифенилы, из трансформаторного и растительного масел. Показано, что наиболее подходящим является использование колонок с полихромом-1, в этом случае требуется меньший расход элюента, степень извлечения одинаковая для всех групп конгенеров ПХБ и составляет $80 \%$. Минимальное определяемое содержание смеси ПХБ при анализе в условиях ГХЭЗД составило $0.002 \%$.

Ключевые слова: полихлорированные бифенилы, растительное масло, трансформаторное масло, газовая хроматография, сорбенты.

\section{Investigation of adsorption gas chromatographic determination of polychlorinated biphenyls in oils}

\author{
Pervova M.G. ${ }^{1}$, Plotnikova K.A. ${ }^{1}$, Shatunova T.V. ${ }^{2}$, Saloutin V.I. ${ }^{2}$ \\ ${ }^{I}$ Ya. Postovskii Institute of organic synthesis UB of RAS, Yekaterinburg \\ ${ }^{2}$ Ural federal university named after the first President of Russia B.N. Yeltsin, Yekaterinburg
}

\begin{abstract}
Polychlorinated biphenyls (PCBs) belong to the group of persistent organic pollutants (POPs). The main sources of PCBs are capacitors and transformers, in which PCBs were used as dielectrics. After the replacement of oils in such equipment, waste oils are formed, in which PCB content must be under control for further use. In addition, due to emergencies edible oils were found to be contaminated with PCBs. The aim of this work is to investigate the employment of multilayer sorption systems based on various sorbents for the development of a method for determination of PCBs in industrial (transformer) and edible (vegetable) oils.

A PCBs mixture consisting of di-, tri-, tetra-, penta-, hexa- and heptachlorobiphenyls prepared from technical mixtures «Trichlorbifenil» and «Sovol» was studied. Multilayer columns with a combination of various sorbents: silica gel, polychrome-1 (polymer based on teflon), polysorb-1 (copolymer of styrene and divinylbenzene), florisil (magnesium silicate), aluminum oxide were used for PCBs extraction. Hexane was the elution solvent. The quantification of recovery rate was carried out using the internal standard method. To obtain more reliable and adequate results, calculations were carried out both for groups of PCB congeners and for the summary of all PCBs. It is shown that use of all multilayer columns with various sorbents allows to achieve 70-90 \% recovery rate. The most acceptable is the use of columns with polychrome-1, in this case the recovery rate is the same for all groups of PCB congeners, and a lower consumption of eluent is required.
\end{abstract}


The minimal detectable PCB content in the transformer oil under the conditions of GC-ECD analysis was $0.002 \%$.

Keywords: polychlorinated biphenyls, transformer oil, vegetable oil, gas chromatography, sorbents.

\section{Введение}

Полихлорированные бифенилы (ПХБ) обладают уникальными теплофизическими свойствами и широко использовались в качестве диэлектриков в конденсаторах и трансформаторах. Однако массовые отравления людей и животных в конце 20го века из-за потребления пищи, приготовленной с использованием пищевых масел или кормов, загрязненных ПХБ, послужили причиной для пристального внимания и контроля за обращением ПХБ. В соответствии со Стокгольмской конвенцией, принятой в 2001 г. [1], к 2028 г. должна быть обеспечена полная экологическая безопасность в отношении этих веществ, а используемые в РФ трансформаторные масла на основе ПХБ необходимо выводить из эксплуатации.

Основным методом анализа ПХБ является газовая хроматография с различными видами детектирования. Главные трудности при определении ПХБ в различных маслах и технологических жидкостях возникают из-за сложного состава исходной матрицы. Минеральные и пищевые масла часто содержат примеси органической и неорганической природы, которые снижают чувствительность детекторов, перегружают систему или элюируются одновременно с целевыми веществами.

В таком случае определение ПХБ напрямую затруднительно, поэтому необходима предварительная процедура пробоподготовки для удаления мешающих соединений или для выделения ПХБ из исходной матрицы. Для этого применяют жидкостную (ЖЭ) и твердофазную экстракцию (ТФЭ), как самостоятельно, так и в совокупности, а также колоночную хроматографию.

Для ЖЭ в качестве экстрагирующего растворителя используют диметилсульфоксид (ДМСО) [2-4] или систему растворителей «ДМСО-деионизированная вода», «этилацетат-гексан» [5]. В большинстве случаев, до стадии экстракции, проводят предварительную обработку растворенного образца масла серной кислотой [6-8], что позволяет избавиться от нежелательных примесей исходной матрицы еще до стадии извлечения и тем самым повысить эффективность следующего этапа.

Для ТФЭ применяют специальные картриджи с различными сорбентами: силикагелями с привитыми октильными $\left(\mathrm{C}_{8}\right)$, октадецильными $\left(\mathrm{C}_{18}\right)$ или аминогруппами $\left(\mathrm{NH}_{2}\right)[2,6,9]$. Кроме того, широко применяются картриджи на основе флорисила $[6,7]$, оксида алюминия [9], различных полимеров [6] и с фазой на основе сульфоксида $[7,10]$. Для фракционного элюирования при ТФЭ используют гексан $[2,7,10]$, ацетонитрил или этилацетат [9].

Процесс очистки путем колоночной хроматографии зачастую требует меньше времени, поскольку позволяет объединить некоторые этапы за счет применения многослойных колонок. Для разделения используют сорбенты на основе силикагеля, оксида алюминия, флорисила, бензосульфоновой кислоты на инертном носителе $[4$, $5,11-13]$. Аналиты элюируют с колонки гексаном $[4,5,11]$ или системой «гександихлорметан» [5, 12, 13].

Количественную оценку извлекаемых ПХБ проводят, как правило, по методу внутреннего стандарта [6, 14-16]. При этом идентификацию проводят по набору определенных («индикаторных») конгенеров.

Целью настоящей работы является исследование использования многослойных сорбционных систем на основе сорбентов различной природы, применение которых на стадии пробоподготовки позволит разработать методику оценки содержа-

Первова и др. / Сорбционные и хроматографические процессы. 2018. Т. 18. № 3 
ние токсичных ПХБ в маслах промышленного назначения (трансформаторное масло) и пищевого качества (растительное масло).

\section{Эксперимент}

ПХБ представляют собой группу органических соединений - изомеров хлорированных бифенилов, которые отличаются друг от друга количеством атомов хлора и их расположением в ароматических ядрах. Индивидуальные изомеры ПХБ называются конгенерами и количество атомов хлора в них находится в интервале от 1 до 10 , а общее число конгенеров ПХБ составляет 209, в зависимости от расположения атомов хлора в структуре проведена нумерация конгенеров ПХБ [17].

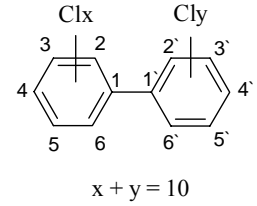

Согласно литературным данным, наиболее часто для градуирования приборов используют стандартные образцы на основе технических смесей ПХБ марок «Арохлор», применяемых в качестве диэлектриков в электротехнических установках в США, с различным составом и содержанием конгенеров. В представленной работе использовали смесь ПХБ, приготовленную на основе отечественных технических смесей ПХБ марок «Трихлорбифенил» и «Совол». Эти технические смеси ПХБ применялись в СССР в качестве диэлектрических жидкостей и до сих пор эксплуатируются в действующих электротехнических установках. Техническая смесь ПХБ марки «Трихлорбифенил» (ОСТ 6-01-43-79) представляет собой смесь ди-, три- и тетрахлорбифенилов [18], а смесь марки «Совол» (ОСТ 6-01-24-85) состоит, в основном, из тетра-, пента- и гексахлорбифенилов [19].

В работе для получения смеси ПХБ, содержащей все группы конгенеров ПХБ, готовили раствор смесей «Трихлорбифенил» и «Совол» в массовом соотношении $1: 1.4$, соответственно. Идентификацию конгенеров ПХБ в полученной смеси ПХБ проводили с использованием данных статей [18-21]. Хроматограмма смеси ПХБ представлена на рис. 1, номера конгенеров ПХБ соответствуют номенклатуре ИЮПАК [17].

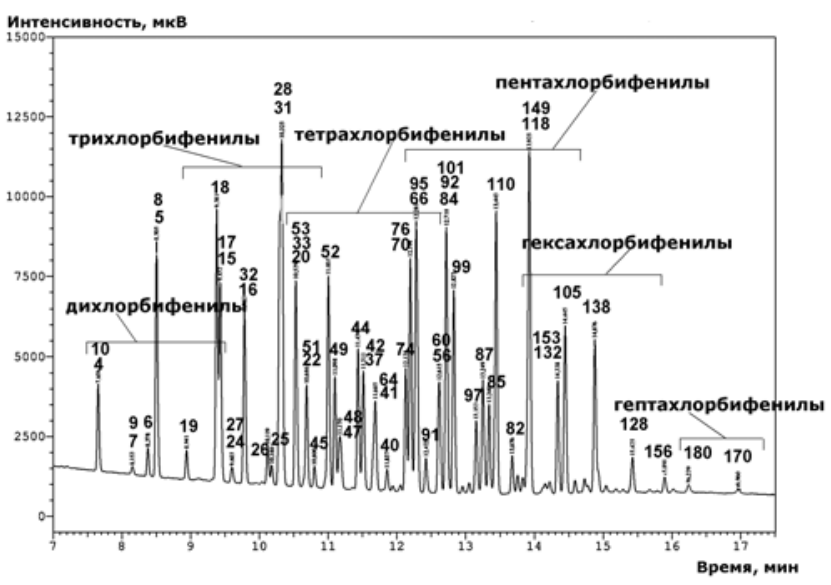

Рис. 1. Хроматограмма исходной смеси ПХБ (условия ГХ-ПИД).

Цифрами указаны номера конгенеров ПХБ согласно номенклатуре ИЮПАК [17]

Оценку содержания групп конгенеров ПХБ в смеси ПХБ проводили по методу внутреннего стандарта, в качестве которого использовали 4,4'-дифторбифенил 
(ГСО № 8534-2004). Для расчета использовали поправочные коэффициенты рассчитанные ранее [18]. Полученные данные представлены в таблице 1.

Таблица 1. Данные исходной смеси ПХБ

\begin{tabular}{|c|c|c|}
\hline Группа ПХБ & Число конгенеров & Содержание, $\%$ \\
\hline Дихлорбифенилы & 8 & 6.52 \\
\hline Трихлорбифенилы & 15 & 23.30 \\
\hline Тетрахлорбифенилы & 18 & 24.58 \\
\hline Пентахлорбифенилы & 13 & 39.49 \\
\hline Гексахлорбифенилы & 6 & 8.67 \\
\hline Гептахлорбифенилы & 2 & 0.39 \\
\hline
\end{tabular}

Извлечение ПХБ из масел проводили колоночной хроматографией с использованием многослойных колонок. Для исключения стадии кислотной обработки использовали слой силикагеля импрегнированного серной кислотой: для этого в силикагель добавляли серную кислоту в массовом соотношении 1.3:1, соответственно. Предварительные опыты показали, что наиболее эффективное извлечение смеси ПХБ из масел происходит при массе каждого из используемых сорбентов 1 г. Многослойные колонки готовили следующим образом: в стеклянную колонку (длиной 250 мм, диаметром 10 мм) со стеклянной мембраной с отверстиями диаметром 1 мм помещали фильтровальную бумагу («Красная лента») и заполняли колонку сверху вниз 1 г силикагеля импрегнированного серной кислотой, 1 г выбранного для эксперимента сорбента, 1 г силикагеля. Характеристики использованных в работе сорбентов представлены в таблице 2. Непосредственно перед использованием оксид алюминия промывали смесью гексан:ацетон в соотношении $1: 1$, отфильтровывали и выдерживали в сушильном шкафу в течение 6-7 ч при температуре $200-230{ }^{\circ} \mathrm{C}$.

Таблица 2. Характеристики используемых сорбентов [22]

\begin{tabular}{|c|c|c|}
\hline Сорбент & $\begin{array}{c}\text { Фирма- } \\
\text { изготовитель }\end{array}$ & $\begin{array}{c}\text { Описание сорбента, средний размер зер- } \\
\text { на сорбента }\end{array}$ \\
\hline силикагель (Sil) & $\begin{array}{c}\text { «Alfa Aеsar», } \\
\text { Великобритания }\end{array}$ & $0.060-0.20$ мм \\
\hline полисорб-1 & «Реахим», РФ & $\begin{array}{c}\text { гидрофобный полимер-гель, сополимер } \\
\text { стирола (60\%) и дивинилбензола (40\%), } \\
0.25-0.50 \text { мм }\end{array}$ \\
\hline полихром-1 & «Реахим», РФ & $\begin{array}{c}\text { фторсодержащий полимер, вырабаты- } \\
\text { ваемый из тефлона марки 4D, } \\
0.20-0.50 \text { мм }\end{array}$ \\
\hline оксид алюминия $\left(\mathrm{Al}_{2} \mathrm{O}_{3}\right)$ & «Aldrich», США & $\begin{array}{c}2 \text { степень активности по Брокману, ще- } \\
\text { лочной, 0.05-0.20 мм }\end{array}$ \\
\hline флорисил & «Fluka», ФРГ & силикат магния, 0.15-0.25 мм \\
\hline
\end{tabular}

Качественный и количественный анализ смеси ПХБ и гексановых фракций после элюирования с многослойных колонок проводили с использованием газового хроматографа «Shimadzu GC-2010 Plus», Япония, с пламенно-ионизационным детектором (условия ГХ-ПИД) или электронозахватным детектором (условия ГХ-ЭЗД) с кварцевой капиллярной колонкой GsBP-5MS, длиной 30 м, диаметром 0.25 мм, толщина пленки 0.25 мкм (полиметилсилоксан, 5\% фенильных групп). Начальная температура колонки $140^{\circ} \mathrm{C}$ (выдержка 1 мин), далее нагрев со скоростью $10^{\circ} \mathrm{C} / \mathrm{Mин,} \mathrm{ко-}$ нечная температура колонки $280^{\circ} \mathrm{C}$ (выдержка 30 мин). Температура испарителя $250^{\circ} \mathrm{C}$, детектора $-300^{\circ} \mathrm{C}$. Газ-носитель - азот, деление потока 1:30, расход через ко- 
лонку $1.0 \mathrm{~cm}^{3} /$ мин. В испаритель хроматографа вводили 1.0 мкл полученных гексановых фракций.

\section{Обсуждение результатов}

Исследование извлечения ПХБ из растительного или трансформаторного масел проводили с использованием модельных растворов масел в гексане с внесением 10,1 и 0.1\% смеси ПХБ, соответственно. В качестве растительного масла использовали подсолнечное масло нерафинированное ГОСТ 1129-2013 (ООО ТД Шишков, Челябинск). Для разделения и выделения ПХБ из растительного масла применяли многослойные колонки с различными системами сорбентов, представленными в табл. 3. В приготовленную колонку вносили $2.0 \mathrm{~cm}^{3}$ раствора масла с внесенной смесью ПХБ в гексане, элюировали гексаном, отбирая фракции по $2.0 \mathrm{~cm}^{3}$, каждую из которых анализировали в условиях ГХ-ПИД. Для количественной оценки степени извлечения объединяли гексановые фракции, содержащие ПХБ, концентрировали, добавляли внутренний стандарт и анализировали.

Таблица 3. Данные извлечения ПХБ из растворов растительного и трансформаторного масел с использованием многослойных колонок (условия ГХ-ПИД)

\begin{tabular}{|c|c|c|c|c|c|}
\hline \multirow[b]{2}{*}{$\begin{array}{l}\text { Внесено } \\
\text { ПХБ, \% }\end{array}$} & \multirow[b]{2}{*}{$\begin{array}{l}\text { Номер } \\
\text { колонки }\end{array}$} & \multirow[b]{2}{*}{$\begin{array}{c}\text { Система сор- } \\
\text { бентов }\end{array}$} & \multirow[b]{2}{*}{$\begin{array}{c}\text { Объем } \\
\text { элюента, см }\end{array}$} & \multicolumn{2}{|c|}{ Найдено $(n=3, P=0.95)$} \\
\hline & & & & $\begin{array}{c}\text { Содержание } \\
\text { ПХБ, \% }\end{array}$ & $\begin{array}{c}\text { Степень извлечения } \\
\text { ПХБ, \% }\end{array}$ \\
\hline \multicolumn{6}{|c|}{ Растительное масло } \\
\hline \multirow{4}{*}{1.18} & 1 & $\begin{array}{c}\mathrm{Sil}\left(\mathrm{H}_{2} \mathrm{SO}_{4}\right) / \\
\text { Sil } \\
\end{array}$ & 16 & $1.00 \pm 0.014$ & 85.0 \\
\hline & 2 & $\begin{array}{c}\mathrm{Sil}\left(\mathrm{H}_{2} \mathrm{SO}_{4}\right) / \\
\text { полихром-1/ } \\
\text { Sil }\end{array}$ & 10 & $1.02 \pm 0.007$ & 86.4 \\
\hline & 3 & $\begin{array}{c}\mathrm{Sil}\left(\mathrm{H}_{2} \mathrm{SO}_{4}\right) / \\
\text { полисорб-1/ } \\
\text { Sil }\end{array}$ & 20 & $0.85 \pm 0.028$ & 72.0 \\
\hline & 4 & $\begin{array}{c}\mathrm{Sil}\left(\mathrm{H}_{2} \mathrm{SO}_{4}\right) / \\
\text { флорисил// } \\
\text { Sil } \\
\end{array}$ & 20 & $1.06 \pm 0.007$ & 89.8 \\
\hline \multicolumn{6}{|c|}{ Трансформаторное масло } \\
\hline \multirow{3}{*}{1.21} & 2 & $\begin{array}{c}\mathrm{Sil}\left(\mathrm{H}_{2} \mathrm{SO}_{4}\right) / \\
\text { полихрром-1/ } \\
\text { Sil } \\
\end{array}$ & 10 & $1.06 \pm 0.07$ & 87.6 \\
\hline & 4 & $\begin{array}{l}\mathrm{Sil}_{\left(\mathrm{H}_{2} \mathrm{SO}_{4}\right) /} \\
\text { флорисил// } \\
\text { Sil }\end{array}$ & 20 & $0.99 \pm 0.01$ & 81.4 \\
\hline & 5 & $\begin{array}{c}\mathrm{Sil}\left(\mathrm{H}_{2} \mathrm{SO}_{4}\right) / \\
\mathrm{Al}_{2} \mathrm{O}_{3} / \\
\mathrm{Sil} \\
\end{array}$ & 30 & $0.86 \pm 0.03$ & 70.7 \\
\hline \multirow{3}{*}{11.72} & 2 & $\begin{array}{c}\mathrm{Sil}\left(\mathrm{H}_{2} \mathrm{SO}_{4}\right) / \\
\text { полихром-1/ } \\
\text { Sil }\end{array}$ & 10 & $9.94 \pm 0.06$ & 84.8 \\
\hline & 4 & $\begin{array}{l}\mathrm{Sil}_{\left(\mathrm{H}_{2} \mathrm{SO}_{4}\right) /} \\
\text { флорисил// } \\
\text { Sil }\end{array}$ & 20 & $9.37 \pm 0.02$ & 80.0 \\
\hline & 5 & $\begin{array}{c}\mathrm{Sil}\left(\mathrm{H}_{2} \mathrm{SO}_{4}\right) / \\
\mathrm{Al}_{2} \mathrm{O}_{3} / \\
\mathrm{Sil} \\
\end{array}$ & 30 & $8.95 \pm 0.04$ & 76.4 \\
\hline
\end{tabular}

Первова и др. / Сорбционные и хроматографические процессы. 2018. Т. 18. № 3 
Для получения более надежных и адекватных результатов все расчеты проводили для групп конгенеров ПХБ. Для этого на хроматограммах объединенных гексановых фракций проводили идентификацию пика каждого конгенера ПХБ и объединяли конгенеры по группам ПХБ. Расчет содержания групп ПХБ проводили по методу внутреннего стандарта, в качестве которого использовали 4,4'дифторбифенил. Степень извлечения для каждой группы ПХБ и общую степень извлечения для всех ПХБ рассчитывали с учетом данных содержания ПХБ в исходной смеси ПХБ.

Для оценки влияния компонентов растительного масла на извлечение ПХБ каждую гексановую фракцию после элюирования с колонки обрабатывали метилатом натрия, поскольку характеристикой пищевых масел является их жирнокислотный состав, определение которого основано на превращении триглицеридов жирных кислот в их метиловые эфиры [23].

Показано, что при использовании любой системы сорбентов компоненты растительного масла не мешают отделению ПХБ и их дальнейшему определению (рис. 2). При извлечении с помощью колонок 1 (с силикагелем), 2 (с полихром-1), 3 (с полисорбом-1) и 4 (с флорисилом) ПХБ элюируются уже с первой фракцией гексана. При использовании колонки 2 (с полихром-1) в шестой фракции ПХБ уже не обнаруживаются, а в случае других систем сорбентов ПХБ регистрируются и в последующих фракциях. Максимальное извлечение ПХБ происходит во второй и третьей фракциях. Установлено, что с использованием таких многослойных колонок степень извлечения ПХБ из раствора растительного масла составляет 70-90 \% (табл. 3).

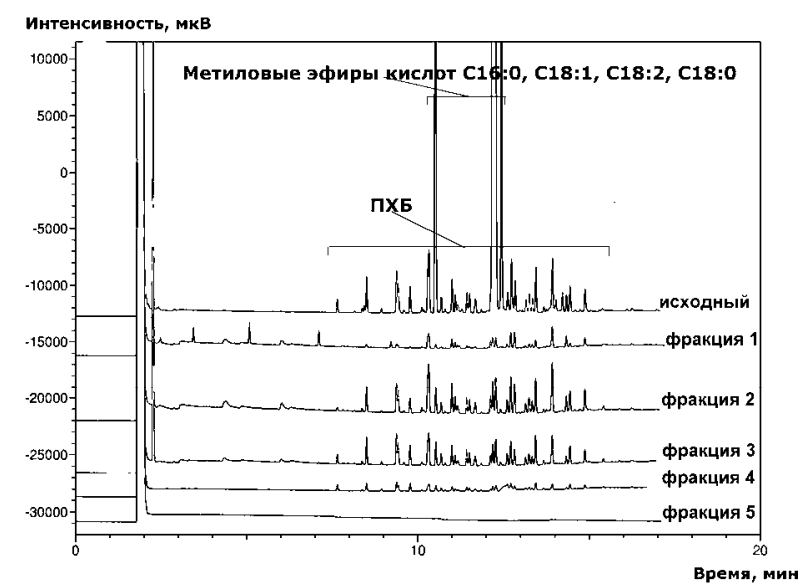

Рис. 2. Хроматограммы исходного раствора растительного масла с внесением $1 \%$ смеси ПХБ и гексановых фракций после разделения на колонке 2 с системой сорбентов $\mathrm{Sil}\left(\mathrm{H}_{2} \mathrm{SO}_{4}\right) /$ полихром-1/Sil (условия ГХ-ПИД)

При сравнении степени извлечения групп конгенеров ПХБ с их исходным содержанием в смеси ПХБ показано, что при использовании колонки 4 (с флорисилом) степень извлечения повышается при переходе от низкохлорированных к средне- и высокохлорированным конгенерам, а при использовании колонки 3 (с полисорбом1), наоборот, понижается при переходе от низко- к высокохлорированным конгенерам. Наиболее оптимальным является использование колонки 2 (с полихром-1), в этом случае степень извлечения одинаковая для всех групп конгенеров.

Для оценки извлечения смеси ПХБ из трансформаторного масла в работе использовали трансформаторное масло марки ТКП (ТУ 38.101890-81). Основные достоинства масла: выступает в роли диэлектрика; подвижно при минусовой температуре; нет воды и прочих веществ; при работе возможно использование в качестве теплоотвода; обладает свойствами противоокислителя. При анализе раствора транс- 
форматорного масла марки ТКП установлено, что масло представляет собой смесь углеводородов линейного и циклического строения от пентадекана $\left(\mathrm{C}_{15} \mathrm{H}_{32}\right)$ до пентатриаконтана $\left(\mathrm{C}_{35} \mathrm{H}_{72}\right)$.

Разделение и выделение ПХБ из трансформаторного масла проводили аналогично по описанной выше методике для определения ПХБ в растительном масле. При использовании колонок 1 (с силикагелем) и 3 (с полисорбом-1) ПХБ начинают элюироваться вместе с трансформаторным маслом, то есть разделения не происходит (рис. 3). А при использовании колонок 2 (с полихромом-1), 4 (с флорисилом) и 5 (с оксидом алюминия) отделение ПХБ от масла происходит, ПХБ смываются последующими порциями гексана. При этом картина извлечения ПХБ из трансформаторного масла колонками 2 (с полихромом-1) и 4 (с флорисилом) совпадает с извлечением из растительного масла - максимальное извлечение во второй и третьей фракциях. При использовании колонки 5 (оксидом алюминия) основное извлечение происходит в третьей, четвёртой и пятой фракциях.

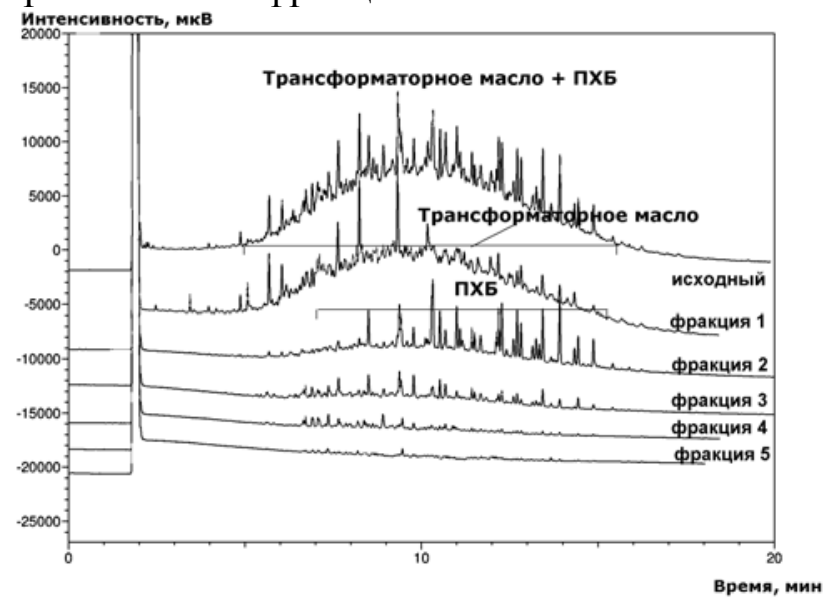

Рис. 3. Хроматограммы исходного раствора трансформаторного масла с внесением $1 \%$ смеси ПХБ и гексановых фракций после разделения на колонке 2 с системой сорбентов $\mathrm{Sil}\left(\mathrm{H}_{2} \mathrm{SO}_{4}\right) /$ полихром-1/Sil (условия ГХ-ПИД

В целом, степень извлечения ПХБ из раствора трансформаторного масла составляет $\sim 80 \%$. Причем наиболее приемлемым является использование колонки с системой сорбентов с полихромом-1, так как в этом случае требуется наименьшее количество гексана для элюирования. Также установлено, что при анализе с ПИД минимальное определяемое содержание ПХБ в трансформаторном масле составило $0.1 \%$. Для определения более низких содержаний ПХБ использовали более чувствительный и селективный электронозахватный детектор (условия ГХ-ЭЗД). Готовили растворы трансформаторного масла с внесением 0.01, 0.005, 0.002 и 0.001\% смеси ПХБ. Для выделения использовали колонку 2 (с полихромом-1), расчет степени извлечения также проводили по методу внутреннего стандарта, в качестве которого использовали гексахлорбензол (ГСО № 7495-98). Установлено, что в этих условиях степень извлечения ПХБ составляет в среднем 87\%, а минимальное определяемое содержание ПХБ в трансформаторном масле составило $0.002 \%$.

\section{Заключение}

С помощью многослойных сорбционных колонок проведено исследование извлечения смеси ПХБ (ди-, три-, тетра-, пента-, гекса- и гептахлорбфенилов) из растительного и трансформаторного масел. Установлено, что использование для извлечения ПХБ всех исследованных колонок с системами сорбентов, в состав которых 
включены сорбенты - силикагель, полихром-1 (полимер на основе тефлона), полисорб-1 (сополимер стирола и дивинилбензола), флорисил (силикат магния) или оксид алюминия, позволяет достичь 70-90 \%-го извлечения ПХБ из масел. Наиболее приемлемым является использование колонок с полихромом-1, в этом случае степень извлечения одинаковая для всех групп конгенеров, требуется меньший расход элюента. Минимальное определяемое содержание ПХБ в трансформаторном масле при анализе в условиях ГХ-ЭЗД составило $0.002 \%$.

\section{Работа выполнена в рамках темы государственного задания ААAА-А18- 118020290124-0 с использованием оборудования Центра коллективного пользования «Спектроскопия и анализ органических соединений» (ЦКП «САОС»).}

\section{Список литературы}

1. Final act of the Conference of Plenipotentiaries on the Stockholm convention on persistent organic pollutants, Stockholm, 22-23 May // UNEP/POPS/CONF/4. United Nations Environment Programme, Geneva. 2001.

2. Takada M., Toda H., Uchida R. // Chemosphere. 2001. Vol. 43. No 4-7. pp. 455-459.

3. Criado M.R., Pereiro I.R., Torrijos R.C. // Journal of Chromatography A. 2004. Vol. 1056. No 1-2. pp. 263-266.

4. Aota A., Date Y., Terakado S., Sugiyama H., Ohmura N. // Analytical Chemistry. 2011. Vol. 83. No 20. pp. 7834-7840.

5. Mahindrakar A.N., Chandra S., Shindle L.P. // Analytical Chemistry: An Indian Journal. 2011. Vol. 10. No 7. pp. 481-486.

6. Yun-Cheol N., Kang-Jin K., Jongki H., Jung-Ju S. // Chemosphere. 2008. Vol. 73. No 1. Supplement. pp. S7-S12.

7. Motladiile S., Kwaambwa H.M., Sichilongo K. // Journal of Chromatography and Separation Techniques. 2011. Vol. 2. No 4. pp. 116123.

8. Martinez H.A.R., Rodriguez G.C., Castillo D.H. // Journal of Mexican Chemical Society. 2005. Vol. 49. No 3. pp. 263-270.

9. Beyer A., Biziuk M. // Food Research Int. 2010. Vol. 43. No 3. pp. 831-837.

10. Numata M., Kaneko T., Mi Q., Ye M. et al. // Journal of Chromatography A. 2008. Vol. 1210. No 1. pp. 68-75.

11. Huang J., Matsumura T., Yu G., Deng S. et al. // Chemosphere. 2011. Vol. 85. No 2. pp. 239-246.

12. Costopoulou D., Vassiliadou I., Chrysafidis D., Bergele K. et al. // Chemosphere. 2010. Vol. 79. No 3. pp. 285-291.
13. López P., Tienstra M., Lommen A., Mol H.G.J. // Food chemistry. 2016. Vol. 211. pp. 645-653.

14. Бродский Е.С., Калинкевич Г.А., Шелепчиков А.А., Фешин Д.Б. и др. // Заводская лаборатория. Диагностика материалов. 2007. T. 73. № 10. C. 13-18.

15. ГОСТ IEC 61619-2014. Жидкости изоляционные. Определение загрязнения полихлорированными бифенилами (РСВ) методом газовой хроматографии на капиллярной колонке. Москва, Стандартинформ. 2015. 32 c.

16. ГОСТ EN 12766-1-2014. Нефтепродукты и отработанные масла. Определение полихлорированных бифенилов (РСВ) и родственных соединений. Часть 1. Разделение и определение выделенных родственных РСВ методом газовой хроматографии (GC) с использованием электронозахватного детектоpa (ECD). М. Стандартинформ. 2015. 48 с.

17. Mills III S.A., Thal D. I., Barney J. // Chemosphere. 2007. Vol. 68. No 9. pp. 16031612.

18. Первова М.Г., Плотникова К.А., Горбунова Т.И., Салоутин В.И. и др. // Журнал общей химии. 2015. Т. 85. № 8. С. 1374-1379.

19. Кириченко В.Е., Первова М.Г., Промышленникова Е.П., Пашкевич К.И. // Аналитика и контроль. 2000. Т. 4. № 1. С. 41-44.

20. Шелепчиков А.А., Бродский Е.С. // Масс-спектрометрия. 2015. Т. 12. № 3. С. 201-109.

21. Mydlova-Memersheimerova J., Tienpont B., David F., Krupcik J. et al. // Journal of Chromatography A. 2009. Vol. 1216. No 32. pp. 6043-6062. 
22. Лурье А.А. Сорбенты и хроматографические носители: справочник. М. Химия. $1972.320 \mathrm{c}$.

\section{References}

1. Final act of the Conference of Plenipotentiaries on the Stockholm convention on persistent organic pollutants, Stockholm, 22-23 May, UNEP/POPS/CONF/4. United Nations Environment Programme, Geneva, 2001.

2. Takada M., Toda H., Uchida R., Chemosphere, 2001, Vol. 43, No 4-7, pp. 455-459. DOI: 10.1016/S0045-6535(00)00394-5.

3. Criado M.R., Pereiro I.R., Torrijos R.C., Journal of Chromatography A, 2004, Vol. 1056, No 1-2, pp. 263-266. DOI: 10.1016/j.chroma.2004.05.080.

4. Aota A., Date Y., Terakado S., Sugiyama H., Ohmura N., Analytical Chemistry, 2011, Vol. 83, No 20, pp. 7834-7840. DOI: 10.1021/ac2015867.

5. Mahindrakar A.N., Chandra S., Shindle L.P., Analytical Chemistry: An Indian Journal, 2011, Vol. 10, No 7, pp. 481-486.

6. Yun-Cheol N., Kang-Jin K., Jongki H., Jung-Ju S., Chemosphere, 2008, Vol. 73, No 1, supplement, $\quad$ pp. S7-S12. DOI: 10.1016/j.chemosphere.2006.12.102.

7. Motladiile S., Kwaambwa H.M., Sichilongo K., Journal of Chromatography and Separation Techniques, 2011, Vol. 2, No 4, pp. 116-123. DOI: 10.4172/2157-7064.1000116.

8. Martinez H.A.R., Rodriguez G.C., Castillo D.H., Journal of Mexican Chemical Society, 2005, Vol. 49, No 3, pp. 263-270.

9. Beyer A., Biziuk M., Food Research Int., 2010, Vol. 43, No 3, pp. 831-837. DOI: 10.1016/j.foodres.2009.11.018.

10. Numata M., Kaneko T., Mi Q., Ye M. et al., Journal of Chromatography A, 2008, Vol. 1210, No 1, pp. 68-75. DOI: 10.1016/j.chroma.2008.09.038.

11. Huang J., Matsumura T., Yu G., Deng S., Yamauchi M. et al., Chemosphere, 2011, Vol. 85, No 2, pp. 239-246. DOI: 10.1016/j.chemosphere.2011.06.023.

12. Costopoulou D., Vassiliadou I., Chrysafidis D., Bergele K. et al., Chemosphere, 2010, Vol. 79, No 3, pp. 285-291. DOI: 10.1016/j.chemosphere.2010.01.024.
23. ГОСТ 30418-96. Масла растительные. Метод определения жирно-кислотного состава. М. Изд-во стандартов. 2001. 116 с.

13. López P., Tienstra M., Lommen A., Mol H.G.J., Food chemistry, 2016, Vol. 211, pp. 645-653.

DOI: 10.1016/j.foodchem.2016.05.041.

14. Brodskii E.S., Kalinkevich G.A., Shelepchikov A.A., Feshin D.B. et al., Zavodskaia laboratoriia. Diagnostika materialov, 2007, Vol. 73, No 10, pp. 13-18.

15. GOST IEC 61619-2014. Zhidkosti izoliacionnye. Opredelenie zagriazneniia polikhlorirovannymi bifenilami (PCB) metodom gazovoi khromatografii na kapilliarnoi kolonke. Moscow, Standartinform, 2015, $32 \mathrm{p}$.

16. GOST EN 12766-1-2014. Nefteprodukty i otrabotannye masla. Opredelenie polikhlorirovannykh bifenilov (PCB) i rodstvennykh soedinenii. Chast' 1 . Razdelenie i opredelenie vydelennykh rodstvennykh metodom gazovoi khromatografii (GC) s ispol'zovaniem elektronozazhvatnogo detektora (ECD). M., Standartinform, 2015, $48 \mathrm{p}$.

17. Mills III S.A., Thal D. I., Barney J., Chemosphere, 2007, Vol. 68, No 9, pp. 1603-1612. DOI: 10.1016/j.chemosphere.2007.03.052.

18. Pervova M.G., Plotnikova K.A., Gorbunova T.I., Saloutin V.I., Chupakhin O.N., Russian Journal of General Chemistry, 2015, Vol. 85, No 8, pp. 1929-1933. DOI: 10.1134/S1070363215080216.

19. Kirichenko V.E., Pervova M.G., Promyshlennikova E.P., Analitika i kontrol', 2000, Vol. 4, No 1, pp. 41-44.

20. Shelepchikov A.A., Brodskii E.S., Massspektrometriia, 2015, Vol. 12, No 3, pp. 201109.

21. Mydlova-Memersheimerova J., Tienpont B., David F., Krupcik J., Sandra P., Journal of Chromatography A, 2009, Vol. 1216, No 32, pp. 6043-6062. DOI: 10.1016/j.chroma.2009.06.049.

22. Lur'e A.A. Sorbenty i khromatograficheskie nositeli: spravochnik. Moscow, Chemistry Publ., 1972, 320 p.

23. GOST 30418-96. Masla rastitel'nye. Metod opredeleniia zhirno-kislotnogo sostava. Moscow, Standart. Publ., 2001, 116 p. 
Первова Марина Геннадьевна - к.х.н., с.н.с. лаборатории фторорганических соединений, Институт органического синтеза им. И. Я. Постовского УрО РАН, Екатеринбург

Плотникова Ксения Антоновна - инженерисследователь лаборатории фторорганических соединений, Институт органического синтеза им. И. Я. Постовского УрО РАН, Екатеринбург

Шатунова Татьяна Викторовна - магистрант кафедры аналитической химии и химии окружающей среды, Уральский федеральный университет им. первого Президента России Б.Н. Ельцина, Екатеринбург

Салоутин Виктор Иванович - д.Х.н., проф., член-корр. РАН, зам. директора по научной работе, Институт органического синтеза им. И. Я. Постовского УрО РАН, Екатеринбург
Pervova Marina G. - Ph.D (chemistry), senior researcher, Laboratory of fluoro-organic compounds, I.Ya. Postovskii Institute of organic synthesis UB RAS, Yekaterinburg, e-mail: pervova@ios.uran.ru

Plotnikova Ksenia A. - Engineer-researcher, Laboratory of fluoro-organic compounds, I.Ya. Postovskii Institute of organic synthesis UB RAS, Yekaterinburg

Shatunova Tat'iana V. - Graduate student (Master's program), Department of analytical chemistry and environmental chemistry,

Ural federal university named after the first President of Russia B.N. Yeltsin, Yekaterinburg

Saloutin Victor I. - Grand Ph.D (chemistry), prof., corr. member of RAS, deputy director (scientific), I.Ya. Postovskii Institute of organic synthesis UB RAS, Yekaterinburg 